\title{
The impact of food supplementation on infant weight gain in rural Bangladesh; an assessment of the Bangladesh Integrated Nutritional Program (BINP)
}

\author{
Housne Ara Begum ${ }^{1}$, CGN Mascie-Taylor ${ }^{2, *}$ and Shamsun Nahar ${ }^{3}$ \\ ${ }^{1}$ Institute of Health Economics, University of Dhaka, Dhaka, Bangladesh: ${ }^{2}$ Department of Biological Anthropology, \\ University of Cambridge, Downing Street, Cambridge CB2 3DZ, UK: ${ }^{3}$ National Institute of Social and Preventive \\ Medicine, Dhaka, Bangladesh
}

Submitted 5 July 2005: Accepted 15 February 2006

\begin{abstract}
Objectives: To examine the efficiency of the Bangladesh Integrated Nutritional Program (BINP) in identifying which infants should be supplemented, whether full supplementation was given for the stipulated period of time, and whether the correct exit criteria from the supplementation programme were used. To test whether targeted food supplementation of infants between 6-12 months of age resulted in enhanced weight gain.

Setting: Mallickbari Union, Bhaluka, a rural area located about $100 \mathrm{~km}$ north of Dhaka, Bangladesh.

Participants: Five hundred and twenty-six infants followed for 6 to 12 months.

Results: Of the 526 infants studied, 368 should have received supplementation based on BINP criteria but only 111 infants (30\%) did so, while a further 13\% were incorrectly given supplementation. So in total over half (52.8\%) of the sample was incorrectly identified for supplementation. In addition, less than a quarter of the infants received the full 90 days of supplementation and close to half of the infants exited the programme without the requisite weight gain. Infants were assigned to one of four groups: correctly supplemented, correctly non-supplemented, incorrectly supplemented or incorrectly non-supplemented. This classification provided natural controls; the correctly supplemented infants versus the incorrectly non-supplemented infants, and the correctly non-supplemented infants versus the incorrectly supplemented infants. There were no significant differences in weight gain between the correctly supplemented group and the incorrectly non-supplemented group or between the correctly nonsupplemented and the incorrectly supplemented groups, nor was there any evidence of growth faltering in the incorrectly non-supplemented group.

Conclusions: This study found serious programmatic deficiencies - inability to identify growth faltering in infants, failure to supplement for the full time period and incorrect exit procedures. There was no evidence that food supplementation had any impact on improving infant weight gain.
\end{abstract}

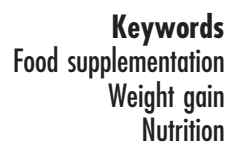

Nutrition
Childhood undernutrition remains a major health problem in many developing countries ${ }^{1,2}$ and food supplementation programmes have been used to alleviate the problem. However, these programmes have been quite heterogeneous, with target groups ranging from all children in the community ${ }^{3-5}$ to high-risk infants and children only $^{6-10}$.

There are also conflicting views on the impact of supplementary feeding trials. In a meta-analysis of supplementary feeding programmes, Beaton and Ghassemi ${ }^{11}$ concluded that the effect of supplementation on anthropometric improvement was surprisingly small while Habicht and Butz ${ }^{12}$ suggested that such feeding, when given in adequate amounts to malnourished children, had a positive effect on growth. Field trials in Colombia, India and Guatemala carried out on supplemented and nonsupplemented children showed that an annual weight gain of $0.50-1.00 \mathrm{~kg}$ can be achieved among young children through supplementary feeding programmes ${ }^{13,14}$.

In Bangladesh, the percentage of $<5$-year-old children suffering from moderate and severe underweight is estimated to be $48 \%$ and 13\%, respectively; $10 \%$ suffer from severe wasting; and 19\% of all children are severely stunted and $30 \%$ are moderately stunted ${ }^{15}$. In order to reduce the extent of malnutrition, in 1995 the Government of the People's Republic of Bangladesh started a food supplementation programme, called the Bangladesh Integrated Nutrition Program (BINP), which was based 
on the Tamil Nadu Integrated Nutrition Programme ${ }^{16}$. The aims of the project were reduce severe protein-energy malnutrition by $40 \%$ and moderate protein-energy malnutrition by $25 \%$ among children $<2$ years old.

The present paper examines the impact of the food supplementation programme on the weight gain of 6-12month-old infants in a rural area of Bangladesh. It also focuses on whether the correct infants were identified to receive supplementation based on the BINP criteria, whether full supplementation was given for the stipulated period of time, and whether the correct exit criteria from the supplementation programme were used.

\section{Participants and methods}

This longitudinal study was conducted from January to December 2002 in Mallickbari Union, Bhaluka, which is located about $100 \mathrm{~km}$ north of Dhaka, the capital of Bangladesh. In the BINP infants received a food supplement (consisting of a cereal-pulse mixture with raw sugar (jaggery) of which approximately $12 \%$ was protein, $8 \%$ fat and the remainder carbohydrate) if their weight gain over the previous three consecutive months was less than $600 \mathrm{~g}$ for $0-11$-month-old children or less than $300 \mathrm{~g}$ for 12-24-month-old children; if there was a loss of weight or no weight gain over the last two months; or if children were suffering from third-degree malnutrition defined by the Gomez classification.

Guardians of infants meeting any of these criteria were asked to asked to take their child to a local community nutrition centre for 6 days each week in order to receive an average ration of $300 \mathrm{kcal} \mathrm{day}^{-1}$ (for severely malnourished) or $150 \mathrm{kcalday}^{-1}$ (for growth faltering) for 3 months. Children exited the supplementary feeding programme if their weight gain over the 3-month feeding period was at least $500 \mathrm{~g}$.

Every attempt was made to measure the baby as close to the birth as possible and thereafter at 30-day intervals. However, the days on which measurements were taken were not consistent, so a 'month' could be as short as 20 days or as long as 45 days. In order to standardise the interval between measurements so that growth changes could be monitored, the predicted weight and length at 30-day intervals were computed for all 526 children individually using a third-order polynomial regression equation (linear, quadratic and cubic terms of the number of days since birth). These equations provided very good fits and explained between 96.7 and 99.9\% of the variance in weight and length. Subsequently the predicted (corrected) weights and lengths of each child at 30-day intervals were computed and these corrected values have been used in all subsequent analyses ${ }^{17}$. In addition, the number of days of supplementary feeding (if any) during the previous month was recorded.

The UNICEF Electronic Scale (UNI-Scale), an automatic solar-powered digital machine, was used to measure the weight of the children. The weight of the child was obtained by first weighing the mother/helper and then the mother/helper holding the child. The machine subtracted the combined mother/helper plus child weight from the mother/helper weight only, so as to give the child weight only to the nearest $0.1 \mathrm{~kg}^{18}$. Inter-observer errors were determined and the technical error of measurement and reliability were calculated. Reliability was $0.99^{19}$.

Statistical analyses were performed using SPSS software, version 11.5 (SPSS Inc., Chicago, IL, USA).

\section{Results}

\section{Identification of children to be supplemented}

A total of 526 children were studied ( $53.6 \%$ male), of whom $25.1 \%$ received supplementation. As shown in Table 1, 368 infants should have received supplementation based on the BINP criteria but only 111 were supplemented. These relative frequencies come from ratios of INS (incorrectly non-supplemented) and CS (correctly supplemented) groups presented in Table 2 . Infants correctly supplemented fell from $78 \%(11 / 14)$ at month 6 to $52 \%(13 /$ 25), 36\% (26/72), 23\% (22/95) and 20\% (31/154) at months 7 to 10 (Table 2), respectively. In addition, 21 infants were incorrectly given supplementation and so over half (52.8\%) of the sample was either not receiving supplementation or being given it incorrectly (Table 1 ). The infants should have received supplementation 6 days a week for 3 months (i.e. 90 days) but as can be seen from Table 3 only slightly more than a quarter (27.3\%) received the daily supplementation for all 90 days. The exit criteria were also not adhered to and over $40 \%$ of infants left the feeding programme without the requisite weight gain.

\section{Commencement of supplementation}

The month of registration for supplementation varied from child to child. Thus, in order to determine the impact of supplementation, the whole study period was divided into a maximum of four periods: i.e. the 3-month period before supplementation commenced, the 3-month supplementation period, the 3-month post-supplementation period and the whole period from 6 to 12 months. So, for example, a child who received supplementation starting in month 6 would have a pre-supplementation period from month 3 to the end of month 5, supplementation from month 6 to the

Table 1 Overall supplementation status of the children

\begin{tabular}{|c|c|c|c|c|c|c|}
\hline \multirow{3}{*}{$\begin{array}{l}\text { Should receive } \\
\text { supplementation }\end{array}$} & \multicolumn{4}{|c|}{ Actually supplemented } & & \\
\hline & \multicolumn{2}{|c|}{ Yes } & \multicolumn{2}{|c|}{ No } & \multicolumn{2}{|c|}{ Total } \\
\hline & $n$ & $\%$ & $n$ & $\%$ & $n$ & $\%$ \\
\hline Yes & 111 & 21.1 & 257 & 48.9 & 368 & 70.0 \\
\hline No & 21 & 4.0 & 137 & 26.0 & 158 & 30.0 \\
\hline Total & 132 & 25.1 & 394 & 74.9 & 526 & 100.0 \\
\hline
\end{tabular}


Efficiency assessment of an infant food supplementation programme

Table 2 Distribution of children in different supplementation groups

\begin{tabular}{lccrrr}
\hline \multirow{2}{*}{$\begin{array}{l}\text { Month of commencement } \\
\text { of supplementation }\end{array}$} & & \multicolumn{4}{c}{ Infant group } \\
\cline { 3 - 6 } & $n$ & CNS & INS & CS & IS \\
\hline 6 & 526 & 512 & 3 & 11 & - \\
7 & 526 & 494 & 12 & 13 & 7 \\
8 & 526 & 451 & 46 & 26 & 3 \\
9 & 526 & 425 & 73 & 22 & 6 \\
10 & 526 & 367 & 123 & 31 & 5 \\
\hline
\end{tabular}

CNS - correctly non-supplemented; INS - incorrectly non-supplemented; CS - correctly supplemented; IS - incorrectly supplemented.

end of month 8 , and a post-supplementation period from month 9 to the end of month 11. For a child receiving supplementation from month 7 , the pre-supplementation period would have been from month 4 to the end of month 6, supplementation from month 7 to the end of month 9 , and a post-supplementation period from month 10 to the end of month 12 .

\section{Weight gain in supplemented and non-supplemented infant groups}

Figures 1 and 2 show the monthly mean weights of supplemented (who commenced at any time between months 6 and 9) and non-supplemented females and males, respectively. Boys had higher mean weights than girls independent of supplementation status. Repeatedmeasures analyses of variance provided no evidence in either sex that supplemented children showed any catchup. Over the whole period supplemented boys were on average $0.49 \mathrm{~kg}$ heavier than supplemented girls $(P=0.003)$ whereas non-supplemented boys were $0.38 \mathrm{~kg}$ heavier than the non-supplemented girls $(P<0.001)$. Analyses also failed to show any significant relationship between the number of days of supplementation and weight gain. Analyses were conducted to determine if there was any association between the number of days a child received supplementation and weight gain in the 90-day period. Regression analyses of weight gain against days of supplementation were undertaken for each supplementation period separately and combined, and no significant linear or curvilinear associations were found.

The analyses were repeated after dividing the children into four groups of $<30$ days, 31-60 days, 61-89 days and 90 days. No significant differences were apparent for any

Table 3 Number of children fulfilling the BINP 90-day supplementation period

\begin{tabular}{lcr}
\hline Days & $n$ & $\%$ \\
\hline$<30$ & 24 & 18.2 \\
$31-60$ & 34 & 25.8 \\
$61-89$ & 38 & 28.9 \\
90 & 36 & 27.3 \\
Total & 132 & 100.0 \\
\hline
\end{tabular}

BINP - Bangladesh Integrated Nutritional Program.

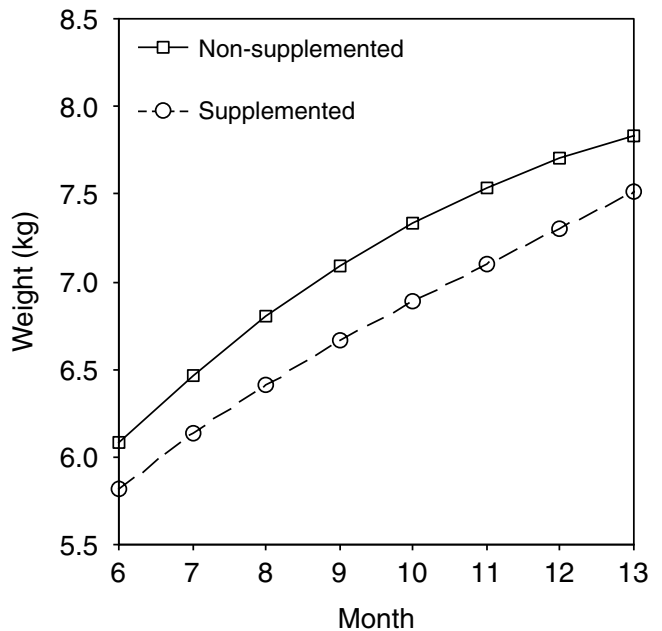

Fig. 1 Monthly mean weight of females by supplementation status

of the supplementation periods, nor were there any obvious trends of increasing weight with more days of supplementation. The overall weight gain independent of the month at which supplementation commenced was determined and no significant association was found with days of supplementation. Analyses which took into account the days of supplementation also failed to show significant differences.

\section{Weight gain in the four infant groups}

In order to test whether the supplementation programme was effective, the infants were divided into the four groups shown in Table 1 ; i.e. those correctly supplemented (CS), those correctly not receiving supplementation (CNS), those who should have received supplementation (INS) and those incorrectly receiving supplementation (IS). These four groups provide two sets of natural controls: correctly supplemented versus those who should have received supplementation, and those correctly not

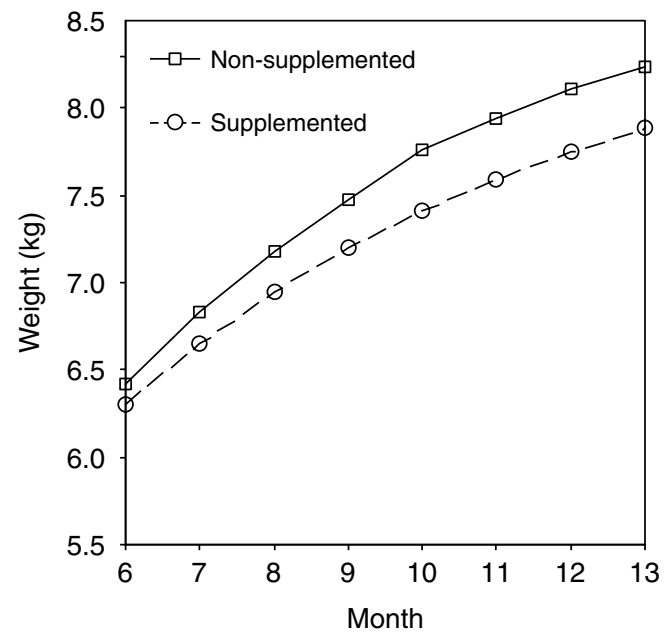

Fig. 2 Monthly mean weight of males by supplementation status 
receiving supplementation versus those incorrectly receiving supplementation. Repeated-measures analyses of variance were conducted separately for commencement of supplementation at months 6 to 9. All analyses indicated that there was some heterogeneity in means between the four groups, but as Fig. 3 illustrates for month 8, the main difference in all months was between the incorrectly supplemented and correctly non-supplemented versus the correctly supplemented and incorrectly non-supplemented. If the programme was having a significant impact there should have been either catch-up of the correctly supplemented group or catch-down in the incorrectly non-supplemented group.

Analyses using incremental weights (monthly changes in weight) revealed significant within-subject variation. There was a tendency in each month and overall for incremental weight to be higher in the correctly nonsupplemented and incorrectly supplemented groups than in the other two groups.

\section{Discussion}

This study indicates serious shortcomings in the implementation of the BINP in this rural area with nearly $70 \%$ of those infants who should have received supplementation not doing so, while 13\% were incorrectly supplemented. Nearly three-quarters of infants failed to receive the full 90 days of supplementation and the exit criterion was not adhered to in $40 \%$ of cases. In June 2000 , the total number of children aged $<2$ years in BINP areas was $437041^{20}$. Extrapolating from the present study would indicate that of the 305929 infants who should receive supplementation, there would be a shortfall of over 200000 infants.

Supplementation commenced when the infant was 6 months of age, in keeping with a number of other studies such as the Integrated Nutrition Project in Tamil Nadu,

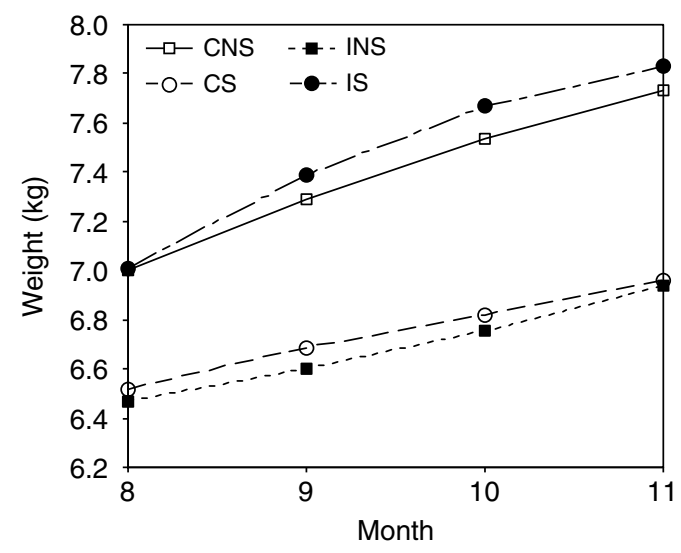

Fig. 3 Monthly mean weight for supplementation starting at month 8 (CNS - correctly non-supplemented; INS - incorrectly non-supplemented; CS - correctly supplemented; IS - incorrectly supplemented)
India $^{16}$ and a recent programme in Guatemala ${ }^{21}$. In the present study 124 children received supplementation but comparisons of supplemented and non-supplemented children revealed that the latter group were heavier each month. In addition, weight gain in the 3 months prior to commencement of supplementation and during the supplementation period was significantly lower in the supplemented than the non-supplemented infant groups.

There was no significant difference in weight gain between the correctly supplemented group and the nonsupplemented groups, or between the correctly nonsupplemented and the incorrectly supplemented groups. If supplementation had some impact then one would expect to see (1) significantly greater catch-up of the correctly supplemented group than of the non-supplemented group or (2) significant growth faltering in the incorrectly non-supplemented group or (3) significantly greater weight gain in the incorrectly supplemented group than in the correctly non-supplemented group.

None of these occurred and the failure to show a significant improvement could be due to a number of factors. First are those involving programme errors, e.g. incomplete days of supplementation, which was also found by Hossain et al. ${ }^{22}$. Second, the food supplied in the BINP may have been used as a replacement not a supplement. This is supported by findings of BINP operational research ${ }^{23}$, which found that $28 \%$ of the children substituted at least part of their domestic food intake by BINP food supplements. Finally, the lack of significant improvement could be attributed to differences in morbidity, which may occur by chance alone or because of the supplement itself. For example, Bhandari et $a l .{ }^{24}$ found that the food supplementation group had significantly higher prevalences of fever and dysentery compared with the control group because of the high risk of contamination during supplementation, but the incidence and prevalence of diarrhoea and acute lower respiratory tract infection were not significantly affected by either intervention. However, many studies have not reported increased morbidity in food supplementation trials or programmes ${ }^{25-34}$.

The results of the present study are in keeping with a recent evaluation of the BINP by Save the Children $\mathrm{UK}^{35}$, which showed that the project had no impact on nutritional status and that rates of malnutrition were the same in project and control areas after 6 years of project implementation. There was some indication that caring practices as reported by mothers were better in project areas, but these had no impact on nutritional status. Save the Children UK also found low levels of effectiveness in supplementary feeding of the project.

The failure to correctly identify children to be supplemented can be improved by training and supervision of field staff. However, motivating mothers to attend feeding centres and ensuring that the food is used as supplement not replacement requires motivation and 
counselling of mothers as to the longer-term benefits that food supplementation will bring their children. If supplementation is to have the desired effect of reducing growth faltering, then further research is needed to determine the appropriate quantity and quality of supplementation for children between 6 months and 2 years of age. Knowledge of the morbidity status and breastfeeding status of the child is essential in the assessment of growth throughout the vulnerable childhood period.

\section{Acknowledgements}

We thank all participants and BINP staff. This work was supported by the Government of the People's Republic of Bangladesh; Churchill College, Cambridge, UK; and the University of Cambridge, UK.

\section{References}

1 United Nations Children's Fund (UNICEF). Children and Development in the 1990s, A UNICEF Source Book. The World Summit for Children. New York: UNICEF, 1990.

2 Bhandari N, Bahl R, Taneja S. Effect of micronutrient supplementation on linear growth of children. British Journal of Nutrition 2001; 85: S131-7.

3 Guzman MA, Scrimshaw NS, Bruch HA, Gordon JE. Nutrition and infection field study in Guatemalan villages 1959-1964. VII. Physical growth and development of preschool children. Archives of Environmental Health 1968; 17: 107-18.

4 Baertl JM, Morales E, Verastegui G, Graham GG. Diet supplementation for entire communities: growth and mortalities of infants and children. American Journal of Clinical Nutrition 1970; 23: 707-15.

5 Gopalan C, Swaminathan MC, Kumari VKK, Rao DH, Vijayaraghavan K. Effect of calorie supplementation on growth of undernourished children. American Journal of Clinical Nutrition 1973; 26: 563-6.

6 Taylor CE, Kielmann AA, DeSweemer C. The Narangwal experiment on interactions of nutrition and infections: 1 . Project design and effects upon growth. Indian Journal of Medical Research 1978; 68: S1-20.

7 Gueri M, Andrews N, Fox K, Jutsum P, St Hill D. A supplementary feeding programme for the management of severe and moderate malnutrition outside hospital. Journal of Tropical Paediatrics 1985; 31: 101-8.

8 Heikens GT, Schofield WN, Dawson S, Grantham-McGregor S. The Kingston Project. I. Growth of malnourished children during rehabilitation in the community, given a high energy supplement. European Journal of Clinical Nutrition 1989; 43: $145-60$

9 Heikens GT, Schofield WN, Christie CD, Gernay J, Dawson S. The Kingston Project. III. The effects of high energy supplement and metronidazole on malnourished children rehabilitated in the community: morbidity and growth. European Journal of Clinical Nutrition 1993; 47: 174-91.

10 Jansen AAJ, Verkley MTB. Ambulatory home nutrition rehabilitation in Kenya. Journal of Tropical Paediatrics 1986; 32: 258-62.

11 Beaton G, Ghassemi H. Supplementary feeding programmes for young children in developing countries. American Journal of Clinical Nutrition 1982; 35: 864-916.

12 Habicht J-P, Butz WP. Measurement of health and nutrition intervention projects. In: Esrey SA, Habicht J-P, Butz WP, eds. A Methodology to Review Public Health Interventions: Results from Nutrition Supplementation and Water Sanitation Projects. Cornell International Nutrition Monograph Series No. 15. New York: Plenum Publishing Corp., 1985; 1-36.

13 Mora JO, Herrera G. The effects of nutritional supplementation on physical growth of children at risk of malnutrition. American Journal of Clinical Nutrition 1981; 34: 1185-92.

14 Habicht J-P. The timing of the effect of supplementary feeding on the growth of rural preschool children. Proceedings of the Ninth International Congress of Nutrition. Basel: Karger, 1972; 199-252.

15 United Nations Children's Fund. Country profile - Bangladesh [online], 2002. Available at http://www.unicef.org/infobycountry/Bangladesh_bangladesh-latest.html/

16 Ghassemi H. Supplementary feeding programmes in developing countries: lessons of the eighties. Asia Pacific Journal of Clinical Nutrition 1992; 1: 131-52.

17 Brush G, Harrison GA, Baber FM, Zumrawi FY. Comparative variability and interval correlation in linear growth of Hong Kong and Sudanese infants. American Journal of Human Biology 1992; 4: 291-9.

18 Lohman TG, Roche AF, Martorell R. Anthropometric Standardization Reference Manual. Champaign, IL: Human Kinetics Books, 1988; 1-93.

19 Ulijaszek SJ, Lourie JA. Errors of measurement. In: Ulijaszek SJ, Mascie-Taylor CGN, eds. Anthropometry: the Individual and the Population. Cambridge: Cambridge University Press, 1994; 30-55.

20 Ministry of Health and Family Welfare, Government of Bangladesh. Monthly Monitoring Report. Bangladesh Integrated Nutrition Project. Dhaka: Ministry of Health and Family Welfare, Government of Bangladesh, 2000.

21 Stein AD, Barnhart HX, Hickey M, Ramakrishnan U, Schroeder DG, Martorell R. Prospective study of proteinenergy supplementation early in life and of growth in the subsequent generation in Guatemala. American Journal of Clinical Nutrition 2003; 78: 162-7.

22 Hossain SMM, Duffield AB, Taylor A. An evaluation of the impact of a US\$ 60 million nutrition programme in Bangladesh. Health Policy and Planning 2005; 20: 35-40.

23 Golden $\mathrm{MH}$. The nature of nutritional deficiency in relation to growth failure and poverty. Acta Paediatrica Scandinavica. Supplement 1991; 374: 95-110.

24 Bhandari N, Bahl R, Nayyar B, Khokhar P, Rohdem JE, Bhan MK. Food supplementation with encouragement to feed it to infants from 4 to 12 months of age has a small impact on weight gain. Journal of Nutrition 2001; 131: 1946-51.

25 Mora JO, Herrera G. The effects of nutritional supplementation on physical growth of children at risk of malnutrition. American Journal of Clinical Nutrition 1981; 34: 1185-92.

26 Lutter CK, Mora JO, Habicht J-P, Rasmussen KM, Robson DS, Herrera MG. Age-specific responsive of weight and length to nutritional supplementation. American Journal of Clinical Nutrition 1990; 51: 359-64.

27 Husaini MA, Karyadi L, Husaini YK, Sandjaj, Karyadi D. Developmental effects of short term supplementary feeding in nutritionally-at-risk Indonesian infants. American Journal of Clinical Nutrition 1991; 54: 799-804.

28 Walker SP, Powell CA, Grantham-McGregor SM, Himes JH, Chang SM. Nutritional supplementation, psychosocial stimulation, and growth of stunted children: the Jamaican study. American Journal of Clinical Nutrition 1991; 54: 642-8.

29 Brown LV, Zeitlin MF, Peterson KE, Chowdhury AMR, Rogers $\mathrm{BL}$, Weld LH, et al. Evaluation of the impact of weaning food messages on infant feeding practices and child growth in rural Bangladesh. American Journal of Clinical Nutrition 1992; 56: 994-1003.

30 Schroeder DG, Kaplowitz H, Martorell R. Patterns and predictors of participation and consumption of supplement 
in an intervention study in a rural Guatemala. Food and Nutrition Bulletin 1993; 14: 191-200.

31 Schroeder DG, Martorell R, Rivera JA, Ruel MT, Habicht J-P. Age differences in the impact of nutritional supplementation on growth. Journal of Nutrition 1995; 125: S1051-9.

32 Caulifield LE, Huffman SL, Piwoz E. Interventions to improve intake of complementary foods by infants 6 to 12 months of age in developing countries: impact on growth and on the prevalence of malnutrition and potential contribution to child survival. Food and Nutrition Bulletin 1999; 20: 183-200.

33 Simondon KB, Gartner A, Berger J, Cornu A, Massamba JP, San Miguel JL, et al. Effect of early, short-term supplementation on weight and linear growth of 4-7 month-old infants in developing countries: a four country randomized trial. American Journal of Clinical Nutrition 1996; 64: 537-45.

34 Lartey N, Manu A, Brown KH, Peerson JM, Dewey KG. A randomized, community-based trial of the effects of improved, centrally processed complementary foods on growth and micronutrient status of Ghanaian infants from 6 to 12 month of age. American Journal of Clinical Nutrition 1999; 70: 391-404.

35 Save the Children UK. Thin on the Ground: A Review of World Bank funded Community Nutrition Projects in Bangladesh, Ethiopia and Uganda. London: Save the Children UK, 2003. 